\title{
Editorial
}

\section{Authorship in Scientific Papers}

\author{
doi: http://dx.doi.org/10.3329/jemc.v6i2.27759
}

Authorship in a scientific research paper implies public responsibility and accountability regarding the contents in the paper. The person who mainly did the research work and wrote the paper is the first or prime author. Prime author is mainly responsible for the integrity of the work as a whole. Other researchers who made substantial contributions to the work are also listed as coauthors. Here we intend to discuss in details on authorship criteria in scientific papers.

We studied the papers obtained from International Committee for Medical Journal Editors, World Health Organization Manual for Biomedical Journal Editors, Stanford online course on Writing in the Sciences and some other related published articles. ${ }^{1-4}$

Contributors making substantial contributions to a paper and shouldering public responsibility of the contents of the paper deserve authorship. The International Committee for Medical Journal Editors recommends that authorship be based on four criteria-

- Substantial contributions to the conception or design of the work; or the acquisition, analysis, or interpretation of data for the work;

- Drafting the work or revising it critically for important intellectual content;

- Final approval of the version to be published; AND

- Agreement to be accountable for all aspects of the work in ensuring that questions related to the accuracy or integrity of any part of the work are appropriately investigated and resolved.

Only those who meet these criteria deserve authorship. Their total involvement should be significant enough and they must take public responsibility for the article's content. Those who do not possess all the four criteria should be acknowledged, but not included as authors. Those who participate in just one or two activities, such as study design, data collection, data analysis or manuscript writing/editing but not in a position to take public responsibility of the contents of the paper should not be offered authorship. Mere possession of an institutional position also does not justify authorship.

\section{Authorship determination}

The individuals who conduct the research will determine who meets the criteria of authorship and ideally it should be done when planning the work, making modifications as appropriate as the work progresses. It is the collective responsibility of the authors to ensure that all the authors enlisted meet all the four criteria of authorship. It is not the role of journal editors to determine who qualifies authorship or to arbitrate authorship conflicts. ${ }^{1}$

\section{Authorship conflicts}

If agreement cannot be reached about who qualifies authorship, the institution/institutions where the research work was done should be asked to investigate the matter. ${ }^{1}$

\section{Removal or addition of an author}

If authors of a scientific paper request removal or addition of an author after manuscript submission or publication of the paper, journal editors should seek an explanation and statement of agreement for the requested change signed by all listed authors including the author to be removed or added.

\section{Corresponding author}

Corresponding author takes the responsibilities for communication with the journal. He/she should also be available after publication to respond to critiques of the work. However, the ICMJE recommends that editors send copies of all correspondence to all the authors enlisted.

\section{Large multi-author group}

When a large multi-author group conducts a work, the group should decide who will be author/authors before 
the work is started. All members named as authors should meet all four criteria of authorship. Some large multi-author groups designate authorship by a group name, with or without names of individuals.

There are also issues of gift authorship, ghost authorship and guest authorship that need to be addressed thoroughly.

\section{Gift authorship}

Heads of departments where the research works are done or supervisors are often enlisted as authors though they do not fulfill authorship criteria. Supervisors should be acknowledged. Sometimes it is difficult for authors to avoid gift authorship. Sometimes there is an unholy alliance among researchers to enlist the names of others as authors without fulfilling authorship criteria. This practice can be minimized or discouraged by journal editors if they require a written statement of the contribution in the research work of all authors. ${ }^{1,4}$

\section{Ghost authorship}

Some researchers, not well in language and not efficient enough to write a scientific paper, take help from others who undertake to rewrite and improve the paper and make the paper suitable for publication. These scientific writers are the 'ghost' authors. Other ghost authors are employed by the pharmaceutical companies who fund the original research. Finding of the research are taken to them and they develop the articles. In both these cases researchers are the authors and they are to take the full responsibility of the content of the papers.

Ghost authors should not be enlisted as authors, but must be acknowledged. ${ }^{2}$

\section{Guest authors}

A 'guest author' is someone whose name appears in a scientific paper's author line even though he/she has not made substantial contribution to qualify him/her as an author of the paper. Some academic researchers who are minimally involved or not involved at all in a paper lend their names as authors (often first author) to bolster the paper's credibility. Guest authorship is offered out of respect or appreciation for an individual in the belief that expert standing of the guest will increase the likelihood of publication, credibility or status of the work.
Pharmaceutical companies independently or in collaboration with medical publishing companies prepare manuscripts and then recruit external, academically affiliated investigators to be authors. Recruited authors are offered honoraria for their participation. $^{1}$

From an internal company email to a potential guest author -

"I would like to invite you to be an author on the abstract and manuscript for this study. We are ... ...

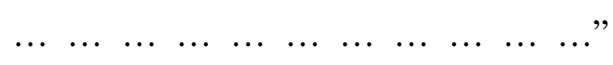

JAMA 2008; 299(15): 1800-1812

Anonymous survey of corresponding authors of articles from top medical journals - Annals of Internal Medicine, JAMA, Lancet, Nature Medicine, New England Journal of Medicine and PLoS Medicine, $17.6 \%$ reported guest authors.

BMJ 2011; 343: d6128

It is dishonest to write anyone's name on the article after it was all done by a company.

\section{Pressured authorship}

This is a variation of guest authorship, where junior researchers often feel pressured to accept or assign authorship to their senior co-workers who have substantial power over their future career. While they are senior figures, often the department head or project supervisor do not fulfill the authorship criteria, but are included because of influential stature. ${ }^{4}$

\section{Conclusion}

Scientific writers must remember that being ethical in authorship is the best policy. Authors should comply with the existing guidelines and keep in mind that signing as a co-author is in itself a responsibility. Giving the credit of authorship to those who cannot defend the published work is not in the interest of genuine authors from the byline. Fairness in writing influences the image of researchers and earns respect 
and credibility for their work. Let's keep it decent as the sweet fruits of authorship can otherwise turn sour.

\section{Md. Aminul Haque Khan}

Professor, Department of Biochemistry

Enam Medical College, Savar, Dhaka

Email: aminhkhan@yahoo.com

\section{Rukhsana Parvin}

Associate Professor, Department of Medicine

Enam Medical College \& Hospital, Savar, Dhaka

\section{Tahmina Yeasmeen}

Assistant Professor, Department of Biology Manarat Dhaka International College, Dhaka

\section{References}

1. Defining the role of authors and contributors. Available at: http://www.icmje.org/recommendations/browse/roles-andresponsibilities. Accessed November 2014.

2. World Health Organization Manual for Editors of Health Science Journals

3. Uniform requirements for manuscripts submitted to biomedical journals: writing and editing for biomedical publication.

4. Writing a scientific research article. Available at: http:// www.garj.org/Writing\%20scientific\%20Journal.htm. Accessed July 2012. 